\title{
Context-specific Enhancement of Glutamate Transmission by Cocaine
}

\author{
Ken Bell, M.S., D.V.M., Patricia Duffy, B.A., and Peter W. Kalivas, Ph.D.
}

The repeated injection of cocaine causes an increase in the capacity of a subsequent acute injection to elevate extracellular glutamate levels in the nucleus accumbens, and the present study sought to determine if the elevation in extracellular glutamate is regulated by the pairing of environmental stimuli with drug administration. Three treatment groups were injected daily for seven days with saline or cocaine $(15 \mathrm{mg} / \mathrm{kg}$, ip); 1) injection of saline in the home cage, 2) injection of cocaine in the home cage (cocaineunpaired), and 3) injection of cocaine in the test apparatus (cocaine-paired). Three weeks following the last daily injection dialysis probes were placed into the nucleus accumbens and all rats were injected with saline followed by cocaine. Basal levels of extracellular glutamate were significantly reduced in the cocaine-paired treatment group. Moreover, only in the cocaine-paired group did the cocaine injection elevate extracellular glutamate. Repeated administration of cocaine also produces an enduring increase in the motor stimulant response to an acute cocaine injection and it was previously found that administration of the $\alpha$-amino-3-hydroxy-5-methylisoxazole-4-propionic acid and kainic acid glutamate receptor antagonist 6-cyano7-nitroquinoxaline-2,3-dione inhibited the sensitized, but not the acute motor, response to cocaine. In this study it was found that the motor stimulant response elicited by cocaine was blunted by pretreatment of the nucleus accumbens with 6-cyano-7-nitroquinoxaline-2,3-dione only in animals receiving daily cocaine injections in the paired environment. In contrast, the N-methyl-D-aspartate glutamate receptor antagonist $R-(-)-3-(2-c a r b o x y p i p e r a z i n-$ 4-yl)-propyl-1-phosphonic acid did not significantly affect cocaine-induced motor activity in any treatment group. These data support a hypothesis that environmental stimuli previously associated with daily cocaine administration can modulate glutamate transmission in the nucleus accumbens in a manner affecting cocaine-induced behavior.

[Neuropsychopharmacology 23:335-344, 2000] (C) 2000 American College of Neuropsychopharmacology. Published by Elsevier Science Inc. All rights reserved.
KEY WORDS: Glutamate; Cocaine; Sensitization; Nucleus accumbens; AMPA; Dialysis

The repeated administration of amphetamine-like psychostimulants produces enduring alterations in the be-

From the Department of Physiology and Neuroscience, Medical University of South Carolina, Charleston, SC

Address correspondence to: Peter Kalivas, Ph.D., Department of Physiology and Neuroscience, Medical University of South Carolina, 167 Ashley Avenue Suite 607, PO Box 250677, Charleston, SC 29425, Tel.: 843-792-4400, Fax: 843-792-4423, Email: kalivasp@ musc.edu

Received December 1, 1999; revised February 1, 2000; accepted February 11, 2000. havioral response to subsequent drug administration. The behavioral adaptations include the induction of paranoia in humans, which has been modeled in rodents as the induction of a sensitized motor stimulant response to psychostimulant injection (Kokkinidis and Anisman 1980; Segal and Schuckit 1983; Robinson and Becker 1986). This animal model has been extensively employed over the last decade to elucidate the cellular adaptations that underlie the behavioral changes associated with repeated psychostimulant use. The research effort has been guided by two facts; 1) a critical molecular site of action for amphetamine-like psychostimulants is the dopamine transporter (Reith et al. 1986; Ritz et al. 1990; although see Rocha et al. 1998), and 2) dopa- 
mine transmission in the mesocorticolimbic dopamine projection from the ventral tegmental area to the nucleus accumbens is critical for the rewarding and motor stimulant actions of this class of drugs (Koob et al. 1993). Knowledge of the molecular action has precipitated the discovery of many cocaine-induced, dopamine-dependent neuroadaptations in the nucleus accumbens (see Nestler et al. 1993; White and Kalivas 1998, for reviews). Arising from this considerable research effort is the awareness that neither the emphasis on dopamine transmission nor the focus on the nucleus accumbens provides a complete profile of the neuroadaptations produced by repeated cocaine (Pierce and Kalivas 1997; Bardo 1998; Wolf 1998).

To some extent, exploration beyond molecular binding of cocaine to dopamine transporters is impelled by a realization that the expression of behavioral adaptations to repeated cocaine is potently regulated by learned associations made between the pharmacological actions of the drug and environmental stimuli (Stewart and Vezina 1988; Robinson et al. 1998). Thus, the daily administration of psychostimulant in a test environment produces more robust behavioral sensitization than when the drug is given in the home environment (Weiss et al. 1989; Dietze and Kuschinsky 1994; Badiani et al. 1997). Due in part to the potent regulation of behavioral sensitization by learned associations, glutamatergic cortical and allocortical brain regions involved in learning and memory have become a focus in the search for substrates mediating behavioral sensitization to cocaine. This research tactic has resulted in the characterization of long-term changes by repeated cocaine administration in both pre- and postsynaptic glutamate transmission (White et al. 1995; Fitzgerald et al. 1996; Pierce et al. 1996; Reid and Berger 1996; Zhang et al. 1997; Ghasemzadeh et al. 1999; Churchill et al. 1999). Specifically, repeated administration of cocaine increases the capacity of a subsequent cocaine injection to elevate extracellular glutamate levels in the nucleus accumbens (Reid and Berger 1996; Pierce et al. 1996). In addition, the sensitized but not the acute motor stimulant effect of cocaine is inhibited by $\alpha$-amino-3-hydroxy-5-methylisoxazole-4-propionic acid (AMPA) receptor antagonist microinjection into the nucleus accumbens (Pierce et al. 1996).

The present study was designed to determine if the changes in glutamate transmission can be regulated by specifically pairing or not pairing an environment with the daily injection of cocaine. The basal and cocaine altered levels of extracellular glutamate in the nucleus accumbens were measured in rats pretreated three weeks earlier with five daily injections of cocaine. In addition, the capacity of glutamate receptor blockade in the nucleus accumbens to inhibit the motor response to cocaine in the paired versus the unpaired environment was examined.

\section{METHODS}

\section{Animals and Surgery}

Male Sprague-Dawley rats weighing between 250-300 g (Simonsen Laboratories, Gilroy, CA) were individually housed with food and water made available ad libitum. A 12 hour light/dark cycle (7 a.m.-7 p.m. light) was used and all experimentation was carried out during the light cycle.

Surgeries were performed five to seven days after the arrival of the subjects to the AAALAC approved housing facility and all experimentation began one week following the operative procedure. Animals were anesthetized with Equithesin $(3.0 \mathrm{ml} / \mathrm{kg}$. ip) and a chronic indwelling guide cannula (20 gauge, 14 $\mathrm{mm}$; Small Parts, Roanoke, VA) was aimed $3 \mathrm{~mm}$ above the dialysis site in the core of the nucleus accumbens $(+1.2 \mathrm{~mm}$ rostral/caudal, $\pm 1.5 \mathrm{~mm}$ medial/ lateral, $-0.5 \mathrm{~mm}$ dorsal/ventral from interaural zero according to the atlas of Pellegrino et al. 1979). The core was targeted because a previous study indicated that the cocaine-induced changes in extracellular glutamate were more robust in the core than in the shell compartment of the nucleus accumbens (Pierce et al. 1996). In another study the same coordinates were employed except chronic bilateral microinjection cannulae (26 gauge, $14 \mathrm{~mm}$; Small Parts) were stereotaxically implanted one $\mathrm{mm}$ over the nucleus accumbens.

\section{Repeated Systemic Treatments}

Following surgery each rat was randomly assigned to one of three treatment groups: 1) rats to receive repeated saline in the home cage (saline-home), 2) rats to receive repeated cocaine in the home cage (cocaineunpaired) or 3) rats to receive repeated cocaine in the test apparatus (cocaine-paired). On the day prior to the start of daily drug injection (day 1), each subject was habituated to a photocell box (Omnitech Electronics, Columbus, $\mathrm{OH}$ ) that was located in a wooden box modified for conducting microdialysis experiments (see below). Each box was equipped with an air and light source, and food and water were present at all times. All rats were attached to the dialysis probe connector; however a dialysis probe was not inserted through the guide cannula into the nucleus accumbens. The adaptation lasted for three hours and the animals were disconnected from the dialysis probe connector and returned to the home cage. On each of the next seven days (days 2 through 8), all subjects were habituated to the dialysis apparatus for one hour. Following habituation, saline-home and cocaine-unpaired subjects were disconnected from the probe connector, returned to their respective home cages and injected one hour later with saline $(1.0 \mathrm{ml} /$ 
$\mathrm{kg}$, i.p.) or cocaine $(15 \mathrm{mg} / \mathrm{kg}$, i.p.), respectively. In contrast, the cocaine-paired subjects were left in the dialysis apparatus attached to the connector, were injected with cocaine $(15 \mathrm{mg} / \mathrm{kg}$, ip) and remained in the dialysis apparatus for three hours after injection. In another set of experiments the treatment groups and repeated saline or cocaine injection regimens were conducted as described above except subjects were not connected daily to the dialysis probe connector. These animals were used for the microinjection study described below.

\section{Microinjection and Glutamate Receptor Blockade}

The day prior to the first microinjection, the rats were placed into the photocell box and given a sham microinjection that consisted of inserting an injector into the nucleus accumbens but not injecting any fluid. Fourteen to 23 days after discontinuing daily treatment with cocaine, rats were adapted to the photocell apparatus for $60 \mathrm{~min}$ and then microinjected with the AMPA/kainate glutamate receptor antagonist 6-cyano-7-nitroquinoxaline-2,3-dione (CNQX; $0.1 \mathrm{nmol}$; Tocus Neuramin, Essex, UK), the NMDA receptor antagonist R-(-)-3-(2-carboxypiperazin-4-yl)-propyl-1-phosphonic acid (CPP; 0.1 nmol; Tocus Neuramin) or vehicle (1\% DMSO in saline) into the core of the nucleus accumbens. The doses of glutamate antagonist were chosen based upon previous studies demonstrated the effectiveness of these doses after intracranial microinjection (Kalivas and Alesdatter 1993; Pierce et al. 1996; Bell and Kalivas 1996). Following a 1-hour adaptation to the photocell cell apparatus (Omnitech Electronics), the obturators were removed from the microinjection guide cannulae and replaced by an injection needle (33 ga stainless steel) which extended $1 \mathrm{~mm}$ below the tip of the guide cannulae into the nucleus accumbens. Bilateral infusions were made over 60 seconds in a volume of $0.3 \mu \mathrm{l} /$ side. Twenty seconds after completing the microinjection the injector was removed and the obturators replaced. Five minutes later the rats were injected with saline $(1.0 \mathrm{ml} / \mathrm{kg}$, ip) or cocaine $(15 \mathrm{mg} / \mathrm{kg}$, ip) and were returned to the photocell apparatus where motor activity was monitored for 120 minutes. After repeated injections rats were divided into either a CNQX or CPP treatment group. At a minimum of three day intervals, each rat received each of four microinjections in random order including: 1) either CNQX $(0.1 \mathrm{nmol})$ or CPP $(0.1 \mathrm{nmol})$ in the accumbens core plus systemic saline; 2$)$ DMSO $(1 \% \mathrm{v} / \mathrm{v})$ vehicle in the core plus systemic saline; 3 ) either CNQX or CPP plus cocaine (15 mg/kg, ip) or 4) DMSO vehicle plus cocaine.

\section{Microdialysis}

The dialysis probes were constructed as described by Robinson and Wishaw (1988), with 1.5 to $2.5 \mathrm{~mm}$ of ac- tive dialysis membrane exposed at the tip. The probes were inserted through the guide cannula into the nucleus accumbens the night prior to the experiment. The next day, dialysis buffer $(5 \mathrm{mM} \mathrm{KCl}, 140 \mathrm{mM}$ $\mathrm{NaCl}, 1.4 \mathrm{mM} \mathrm{CaCl}_{2}, 1.2 \mathrm{mM} \mathrm{MgCl}_{2}, 5.0 \mathrm{mM}$ d-glucose, plus $0.2 \mathrm{mM}$ phosphate-buffered saline to give a $\mathrm{pH}$ value of 7.4 and a final sodium concentration of 140.7 $\mathrm{mM}$ ) was advanced via a syringe pump (Harvard Instruments, Boston, MA) through the probe at a rate of $1.9 \mu \mathrm{l} /$ minute for two hours prior to collecting baseline dialysis samples. 20-minute baseline samples were collected, followed by an injection of saline $(1.0 \mathrm{ml} / \mathrm{kg}$, ip). After collecting six more samples (120 minutes), cocaine (15 mg/kg, ip) was injected and eight more dialysis samples (160 minutes) were collected.

\section{Quantification of Glutamate Content}

The concentration of glutamate was determined using HPLC with fluorometric detection. The dialysis samples were collected into $10 \mu \mathrm{l}$ of mobile phase containing 2.0 pmoles of homoserine as the internal standard. The mobile phase for glutamate is described by Donzanti and Yamamoto (1988). A reversed-phase column (10 cm; ODS) was used to separate the amino acids and precolumn derivatization of amino acids with o-phthaldehyde was performed using an autosampler. Glutamate was detected by a fluorescence spectrophotometer (Shimadzu, Columbia, MD) using an excitation wavelength of $300 \mathrm{~nm}$ and an emission wavelength of $400 \mathrm{~nm}$. Peak heights were measured and compared to an external standard curve for quantification.

\section{Histology}

At the end of each study, all subjects were sacrificed for histological verification of cannula placement. Subjects were given an overdose of pentobarbital and sequentially perfused transcardially with warm PBS and a $4 \%$ formaldehyde solution. The brains were removed and stored in formaldehyde overnight, then coronally-sectioned at $100 \mu \mathrm{m}$ through the site of microinjection with a vibratome. The sections were mounted on gelatin-coated slides and stained with cresyl violet. An animal was used for data analysis if at least $50 \%$ of the active region of the probe traversed the core of the nucleus accumbens. In some subjects as much as $50 \%$ of the probe was dorsal to the nucleus accumbens in the striatum or ventral in the olfactory tubercle. In order to be included in data analysis it was required that the tips of the microinjection cannulae were bilaterally located in the core of the nucleus accumbens, similar to what is shown elsewhere (Pierce et al. 1996). 
Table 1. Basal Levels of Extracellular Glutamate in the Nucleus Accumbens

\begin{tabular}{lcc}
\hline Treatment Group & N & $\begin{array}{c}\text { Glutamate } \\
\text { (Pmol/Sample) }\end{array}$ \\
\hline Saline/home & 10 & $111.8 \pm 31.2$ \\
Cocaine/unpaired & 14 & $68.0 \pm 15.9$ \\
Cocaine/paired & 19 & $45.3 \pm 8.6^{*}$ \\
\hline
\end{tabular}

Basal values were determined by averaging the three baseline samples for each animal. The data were statistically evaluated using a one-way ANOVA followed by a Fisher's PLSD post hoc comparison $\left(\mathrm{F}_{(2,40)}=3.72\right.$, $p=0.033$.

${ }^{*} p<.05$, compared with saline/home

\section{Data Analyses}

In the microdialysis experiment the basal levels of glutamate were significantly different between treatment groups (see Table 1). Therefore, the raw data were statistically evaluated using a two-way ANCOVA. In addition, the data were normalized to percent change from the average basal level of glutamate in each animal and analyzed using a two-way ANOVA with repeated measures over time. In the microinjection study comparisons of total photocell beam breaks over one hour after injection were made using a two-way ANOVA and the time-courses of behavioral data were evaluated using a two-way ANOVA with repeated- measures over time. When significant interaction $\mathrm{F}$ scores were identified, post hoc comparisons between acute treatments within each chronic treatment condition were performed using a one-way repeated measures ANOVA, while post hoc comparisons between chronic treatment groups were made using a least significant difference test (Milliken and Johnson 1984).

\section{RESULTS}

\section{Cocaine Pairing with the Environment Augments Extracellular Glutamate in the Nucleus Accumbens}

Figure 1 shows the effect of saline and cocaine $(15 \mathrm{mg} /$ $\mathrm{kg}$, ip) administration on extracellular glutamate levels in the nucleus accumbens. The raw data shown in panel A reveal that the basal levels of extracellular glutamate differ between the treatment groups. The baseline data are summarized in Table 1, which shows that the level of extracellular glutamate was significantly reduced in the animals treated with cocaine in the paired environment. The group injected with cocaine in the home cage (cocaine-unpaired) showed intermediate values and did not significantly differ from either of the other two groups.

Evaluation of the raw data in Figure 1A using a twoway ANCOVA with basal values as the covariant re-
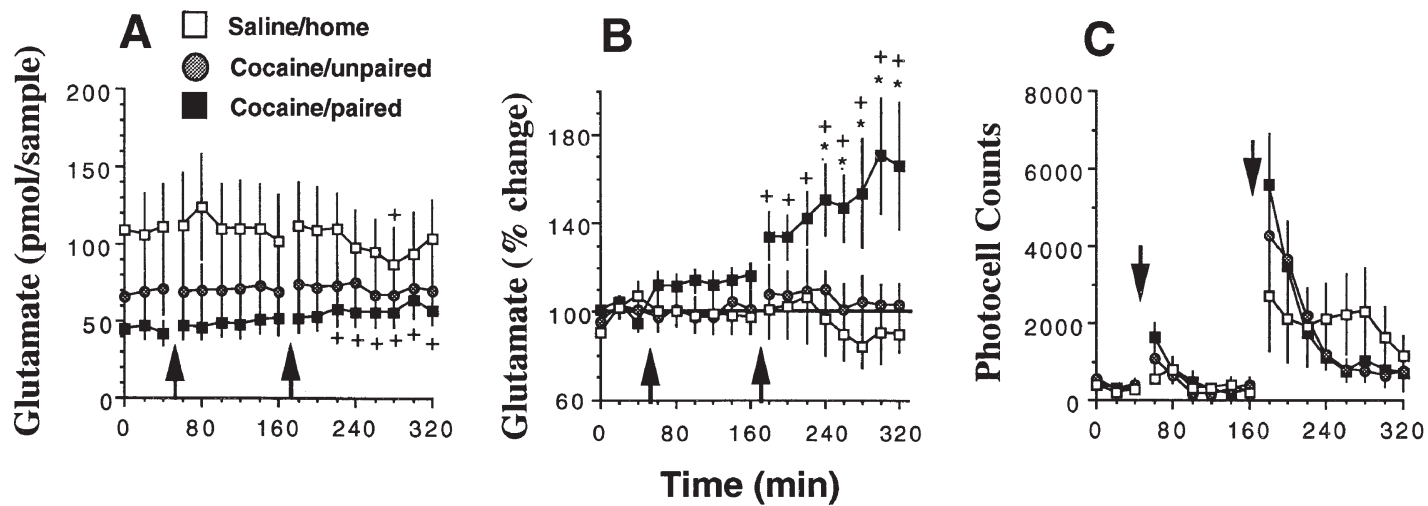

Figure 1. Cocaine increases extracellular glutamate only in the cocaine-paired subjects. Rats were administered daily cocaine or saline and three weeks later microdialysis was conducted in the nucleus accumbens. After collecting baseline samples, the subjects were injected with saline (first arrow; $1 \mathrm{ml} / \mathrm{kg}$, ip), followed by an injection of cocaine (second arrow; $15 \mathrm{mg} / \mathrm{kg}$, ip). Panel A shows the raw data as mean \pm sem pmol/sample, panel B shows the data normalized to basal levels as mean \pm sem percent change, and panel $C$ shows the accumulation of horizontal photocell beam breaks obtained simultaneously with collecting the dialysis samples. The data are shown as mean \pm sem horizontal photocell counts accumulated over 20-minute intervals. For panels A and B the number of determinations in each group is indicated in Table 1. Behavioral data were not obtained for all animals due to technical difficulties and the $\mathrm{N}$ in each treatment group for panel $\mathrm{D}$ is as follows: saline $/$ home $=9$; cocaine $/$ unpaired $=11$; cocaine $/$ paired $=18$. The data were statistically evaluated using a two-way ANOVA (panels B and C) or ANCOVA (panel A) with repeated measures over time, and the significant F scores are shown in the text.

${ }^{*} p<.05$, comparing all groups with saline-home using a least significant difference post hoc comparision (Milliken and Johnson 1984).

$+p<.05$, comparing baseline to times after saline or cocaine injection within each chronic treatment group using a one-way ANOVA with repeated measures over time. 
vealed a significant covariance $(\mathrm{F}[1,39]=332.0 ; p<$ $.001)$, as well as a significant effect of acute treatment $(\mathrm{F}[1,39]=5.50 ; p=.024)$ and interaction between acute treatment and basal values $(\mathrm{F}[1,39]=10.72 ; p=.002)$. Post hoc evaluation revealed a significant difference from baseline beginning at 60 minutes after cocaine administration (i.e. time $=220$ minutes in Figure 1A) in the cocaine-paired treatment group that continued for the duration of the experiment. A significant difference was also measured between basal values and $120 \mathrm{~min}-$ utes after cocaine injection (i.e. time $=280$ minutes) in the saline-home group. No significant differences between baseline and saline or cocaine treatments were measured in the cocaine-unpaired group.

Because the baseline values were significantly different from each other, the data were normalized to percent change from the average baseline value for each animal. Figure $1 \mathrm{~B}$ reveals that there was a significant treatment effect $(\mathrm{F}[2,40]=3.86 ; p=.030)$, a significant change over time $(\mathrm{F}[17,680]=3.67 ; p<.001)$, and a significant interaction between time and treatment $(\mathrm{F}[34,680]=2.20 ; p<$ $.001)$. Injection of saline $(1.0 \mathrm{ml} / \mathrm{kg}$, ip) did not alter the levels of glutamate in any treatment group. However, post hoc analysis revealed that the cocaine-paired group showed an increase in extracellular glutamate in response to an injection of cocaine $(15 \mathrm{mg} / \mathrm{kg}$, ip) beginning in the first 20 minutes after injection for the duration of the experiment. Cocaine produced no significant change in the other chronic treatment groups, and the cocaine-induced elevation in glutamate in the cocaine-paired group was significantly greater than glutamate levels in the other two treatment groups beginning at 80 minutes after injection of cocaine.

Figure $1 \mathrm{C}$ shows the accumulation of photocell beam breaks obtained in association with collecting dialysis samples. A two-way ANOVA with repeated measures over time revealed a significant effect of time $(\mathrm{F}[17,578]=$ 17.59; $p<.001$ ), but no difference between treatment groups or an interaction between treatment group and time.

\section{Effect of CNQX and CPP on the Behavioral Response to Cocaine}

Figures 2 and 3 show the effect of blocking AMPA and NMDA receptors in the nucleus accumbens on the behavioral response to an injection of cocaine or saline made two to three wks after discontinuing daily cocaine or saline injections. Separate two-way ANOVAs with repeated measures over acute injection were used to evaluate the CNQX and CPP treatment groups. There was a significant effect of acute treatment in the CNQX group $(\mathrm{F}[3,72]=39.47, p<.001)$, but no effect of chronic treatment group nor any interaction between chronic and acute treatments. Post hoc analysis was conducted using a one-way repeated measures ANOVA in over each
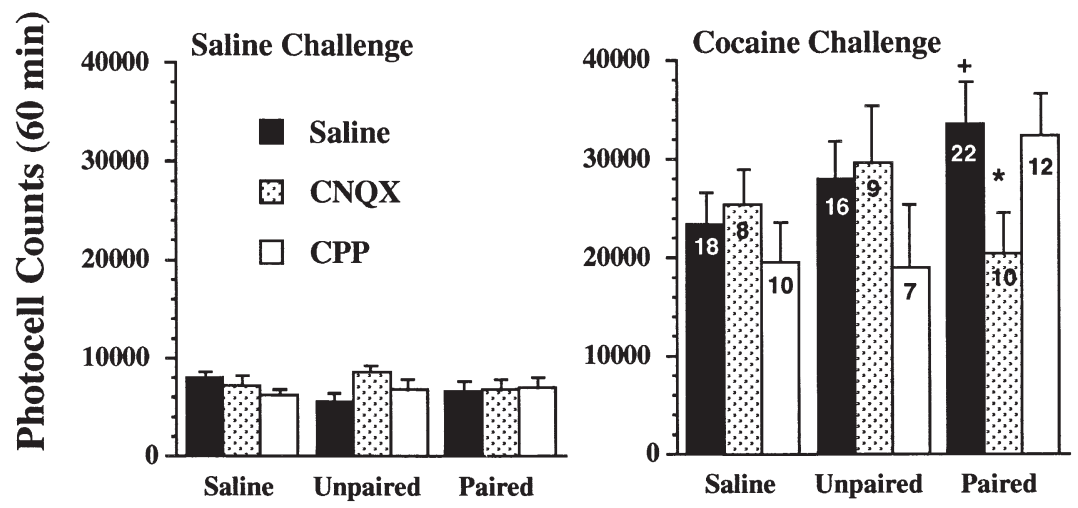

Figure 2. Blockade of AMPA glutamate receptors in the nucleus accumbens inhibits the behavioral response to cocaine only in the cocaine-paired subjects. Rats were divided into three daily drug treatment groups, including those given saline or cocaine in the home environment (home and unpaired, respectively) and those given cocaine in the photocell apparatus (paired). At two to three weeks after the last injection of daily cocaine or saline subjects were administered four different treatments given in random order using a 72- hour intertrial interval. The treatments consisted of all possible combinations of 1) $1 \%$ DMSO vehicle $(0.5 \mu \mathrm{l} /$ side $)+$ saline $(1 \mathrm{ml} / \mathrm{kg}$, ip $), 2)$ CNQX $(0.1 \mathrm{nmol} / \mathrm{side})+$ saline, 3$) 1 \%$ DMSO vehicle + cocaine $(15 \mathrm{mg} / \mathrm{kg}$, ip) or 4) CNQX + cocaine. In another group of animals the NMDA antagonist CPP (0.1 nmol) was substituted for CNQX. The data are shown as the total number of horizontal photocell counts measured during the first 60 minutes after treatment and the number of determinations in each group is indicated in the bar. All data were statistically evaluated using a two-way ANOVA (see text for significant F scores).

${ }^{*} p<.05$, comparing Sa/Cocaine with CNQX/Cocaine or CPP/Cocaine using a one-way ANOVA with repeated measures over microinjection treatments.

$+p<.05$, comparing Sa/Cocaine in the saline-home group to the other two daily treatment groups using a one-way ANOVA. 

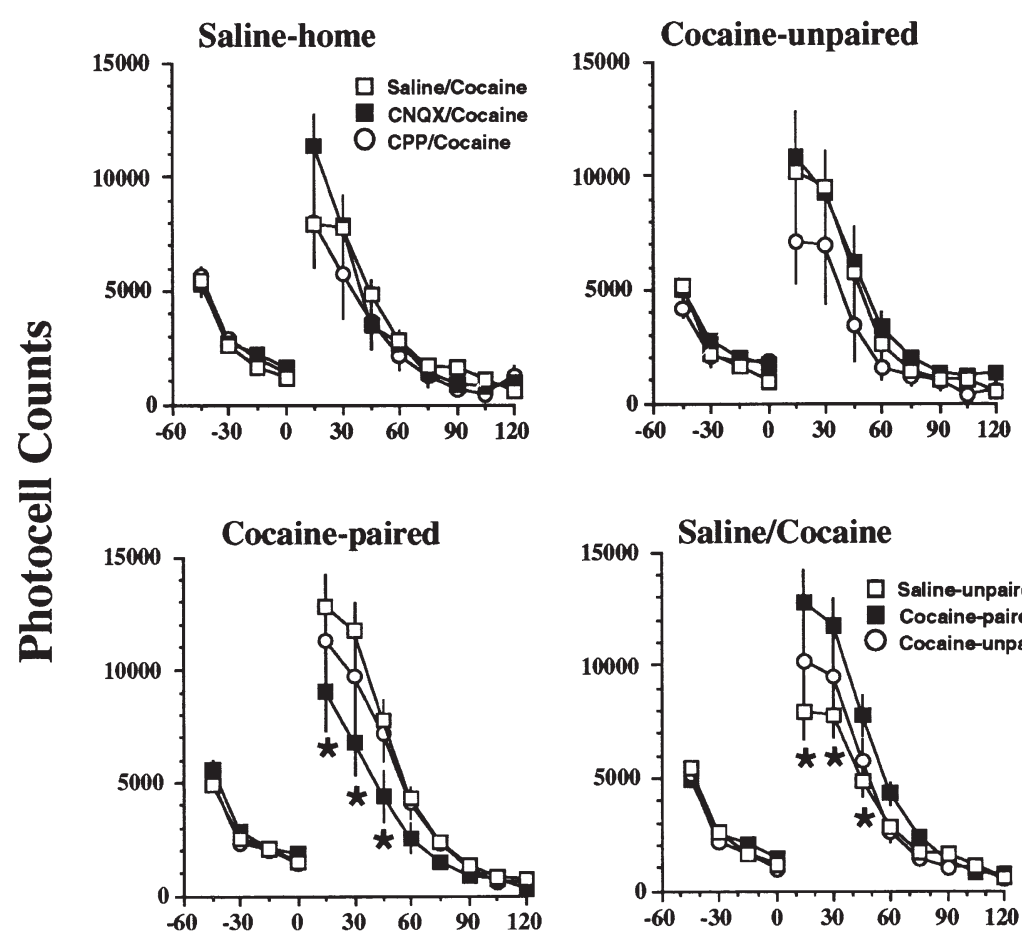

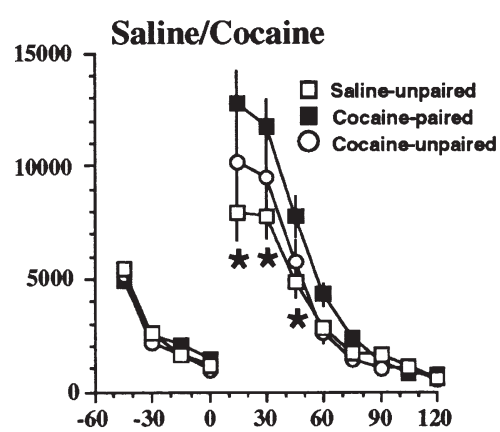

Figure 3. The time course of the behavioral data showing the capacity of CNQX to inhibit cocaine induced motor activity in the group of rats that were pretreated with daily cocaine in the test environment. An additional panel (Saline/Cocaine) shows the time course for the response to cocaine alone in each of the three chronic treatment groups. The data were derived from those shown in Figure 2 and are shown as mean \pm sem horizontal photocell counts. The data were statistically evaluated using a twoway ANOVA with repeated measures over time.

$* p<.05$, comparing Saline/Cocaine with CNQX/Cocaine using a least significant difference post hoc analysis (Milliken and Johnson 1984).

\section{Time (min)}

chronic treatment group. In all groups the cocaine significantly elevated motor activity, but only in the cocaine-paired group did CNQX reduce cocaineinduced motor activity. In the CPP treatment group the only significant effect was acute treatment $(\mathrm{F}[3,72]=39.23, p<.001)$. The post hoc analysis revealed that cocaine elevated motor activity in all groups, but in no group did CPP alter the stimulant effect of cocaine.

Figure 3 shows the time course of the behavioral response produced by cocaine in each of the treatment groups. Pretreatment of the nucleus accumbens with CNQX significantly reduced the motor response to cocaine only in the cocaine-paired group (drug $\mathrm{F}(2,42)=$ $2.24, p=.119$; time $\mathrm{F}(11,462)=95.50 ; p<.001$; interaction $\mathrm{F}(22,462)=1.92, p=.008)$. A least significant difference post hoc analysis revealed a significant reduction by CNQX during the first 60 minutes after cocaine administration. Neither glutamate receptor antagonist altered cocaine-induced motor activity in the saline-home treatment group (drug $\mathrm{F}(2,29)=0.32, p=.730$; time $\mathrm{F}(11,319)=68.71, p<.001$; interaction $\mathrm{F}(22,319)=$ $1.54, p=.059)$ nor in the cocaine-unpaired treatment group (drug $\mathrm{F}(2,29)=1.54, p=.232$; time $\mathrm{F}(11,319)=$ 50.96; $p<.001$; interaction $\mathrm{F}(22,319)=0.70, p=.814)$. Figure 3 also compares the response to cocaine between the three chronic treatment groups and reveals that behavioral sensitization was present during the first 60 minutes after cocaine administration compar- ing the saline-home with the cocaine-paired group (chronic $\mathrm{F}(2,53)=3.59, p=.035$; time $\mathrm{F}(11,583)=$ 116.06, $p<.001$; interaction $\mathrm{F}(22,583)=2.87, p<$ $.001)$. The cocaine-unpaired group showed intermediate values indicating that the sensitized motor response was only partly a conditioned response.

\section{DISCUSSION}

The data in this study demonstrate that pairing daily cocaine administration with a specific environment augments the capacity of cocaine to elevate extracellular glutamate in the nucleus accumbens. Moreover, the lack of effect by AMPA/kainate receptor blockade in the cocaine-unpaired or saline control treatment groups indicates that glutamate transmission is consequential in the motor response only when cocaine-associated environmental cues are present.

\section{Glutamate Transmission and Cocaine}

Previous studies have shown that cocaine alters glutamate transmission in the nucleus accumbens. The acute systemic administration of a high dose of cocaine increases extracellular glutamate in the nucleus accumbens (Smith et al. 1995; Reid et al. 1997), and after repeated cocaine treatment a lower dose of cocaine produces a rapid and enduring elevation in extracellular 
glutamate (Pierce et al. 1996, 1998; Reid and Berger 1996). Moreover, by employing an arbitrary criterion to separate daily cocaine-treated subjects that developed behavioral sensitization from those that did not, Pierce et al. (1996) found that the most robust effect of cocaine on extracellular glutamate was measured in the animals developing sensitization. Since previous studies clearly show that the expression of behavioral sensitization is promoted by the presence of environmental stimuli specifically associated with previous drug injections (Weiss et al. 1989; Stewart 1991), it was hypothesized that the changes in glutamate transmission might mediate this learned association. The present data provide partial support for this postulate since only animals given cocaine paired with the test environment showed elevated extracellular glutamate levels. Moreover, blocking AMPA/kainate receptors in the nucleus accumbens attenuated the motor; response in animals receiving daily cocaine in the test environment while it was without effect in the other treatment groups.

In spite of differences in extracellular glutamate there was no difference in the behavioral response to cocaine between treatment groups in the dialysis study. This is inconsistent with the concept that the elevation in extracellular glutamate is mediating behavioral sensitization in the paired environment. Moreover, the most robust differences in extracellular glutamate occurred beyond one hour after cocaine administration, which differs from the peak behavioral response elicited by cocaine that occurs during the first hour. Thus, while the elevation in extracellular glutamate may be permissive to the expression of behavioral sensitization, it is not a sufficient stimulus to elicit behavioral augmentation. However, the fact that CNQX microinjection inhibited the motor response to cocaine only in the cocainepaired group supports a necessary role for glutamate transmission in the nucleus accumbens in the regulation of cocaine-induced motor behavior by environmental stimuli. Moreover, this dose of CNQX did not affect the acute motor response to cocaine in the saline-home group indicating a more critical role for glutamate in the repeated versus the acute effects of cocaine. Finally, it was reported that the motor response elicited by AMPA receptor stimulation in the nucleus accumbens is augmented in rats pretreated with daily cocaine (Pierce et al. 1996), and Bell and Kalivas (1996) demonstrated that the cross-sensitization between cocaine and AMPA is manifested only in a cocaine-paired environment. Taken together these data provide evidence for involvement of glutamate transmission in the nucleus accumbens when cocaine is administered in the presence of environmental stimuli previously associated with cocaine. However, the data also indicate that the in- crease in glutamate transmission alone is not sufficient to elicit behavioral sensitization.

While used primarily as an AMPA/kainate antagonist, CNQX has some affinity for the NMDA receptors, posing possible involvement of this ionotropic glutamate receptor subtype. However, the selective competitive NMDA antagonist CPP was without effect on cocaine-induced motor activity in the cocainepaired treatment group. Interestingly, CPP produced a trend towards a reduction in motor activity in the cocaine-unpaired and saline-home treatment groups. This may indicate a role for NMDA receptors in the unconditioned motor responses to cocaine and is consistent with previous studies showing that relatively high doses of NMDA antagonists in the nucleus accumbens inhibit the motor response to an acute injection of cocaine (Pulvirenti et al. 1991).

\section{Possible Anatomical Substrates}

There are many possible neuronal sources of glutamate in the nucleus accumbens, including the prefrontal cortex, amygdala, hippocampus and periventricular thalamus (Deutch et al. 1993). Lesioning these brain nuclei either before or after administering repeated psychostimulant injections reveals that the prefrontal cortex may play a role in both the development and expression of behavioral sensitization, while lesions of the amygdala attenuated the development but not the expression of sensitization (Wolf et al. 1995; Browman et al. 1996; Pierce et al. 1998; however, see $\mathrm{Li}$ et al. 1999). Moreover, electrical stimulation of the prefrontal cortex, but not the hippocampus, produced behavioral sensitization to cocaine (Schenk and Snow 1994), and lesions of the dorsal prefrontal cortex (e.g. prelimbic and anterior cingulate cortices; Paxinos and Watson 1986) inhibited the capacity of cocaine to elevate extracellular glutamate in the nucleus accumbens in rats pretreated with repeated cocaine injections (Pierce et al. 1998). Taken together, these data are consistent with a hypothesis that the projection from the dorsal prefrontal cortex to the nucleus accumbens is important in the expression of behavioral sensitization to cocaine. That cortical glutamatergic projections may be especially important in the interaction between pharmacological effects of cocaine and drug paired environmental stimuli is supported by imaging studies in human cocaine addicts. Recent studies reveal that craving for cocaine induced by the presentation of stimuli previously paired with cocaine use increases metabolic activity in the anterior cingulate cortex and amygdala (Grant et al. 1996; Childress et al. 1999).

\section{The Source of Extracellular Glutamate and Technical Concerns with Dialysis}

The relevance of dialysis measures of extracellular glutamate to ongoing neuronal activity is of some con- 
cern. Most studies find that the basal level of extracellular glutamate is not reduced by blocking voltage-dependent calcium or sodium channels (Timmerman and Westerink 1997). In a previous study, we found that while the basal levels of extracellular glutamate were not sensitive to tetrodotoxin (TTX) blockade of sodium channels, the initial 20 to 40 minutes of the increase in extracellular glutamate elicited by an injection of cocaine was antagonized by TTX (Pierce et al. 1996). Further supporting neuronal involvement, the rise in extracellular glutamate produced by systemic cocaine administration was inhibited by lesions of the glutamatergic afferents to the nucleus accumbens arising from the prefrontal cortex (Pierce et al. 1998). Nonetheless, a contribution by nonvesicular glutamate is likely and probably accounts for the majority of the increase during the last two hours after administering cocaine (see Pierce et al. 1996; Xue et al. 1996; Wolf 1998, for further discussion of this possibility).

The source of the reduction in basal extracellular glutamate in the cocaine-paired environment is also difficult to discern with microdialysis. Given the apparently small contribution by vesicular glutamate towards the basal extracellular levels of glutamate (Timmerman and Westerink 1997), it seems likely that the reduction may arise from enhanced elimination of glutamate from the extracellular space via increased re-uptake. Glial transporters provide the greatest quantitative contribution to glutamate uptake in the brain (Rothstein et al. 1996). However, there is no clear mechanism by which different environmental stimuli can modulate glial function. Alternatively, cysteine-glutamate exchange makes a contribution towards maintaining extracellular glutamate levels in the brain (Warr et al. 1999; Jabaudon et al. 1999), and it is possible that the environment may modify this process.

Regardless of the source of extracellular glutamate, three observations in the present report support the potential functional relevance of the changes in extracellular glutamate. 1) The enduring reduction in basal extracellular levels of glutamate associated with placement of daily cocaine pretreated subjects in the cocaine-paired environment indicates that environmental context contributes to an alteration in glutamate disposition in the nucleus accumbens. 2) Only rats receiving cocaine in the drug-paired environment demonstrate enhanced responsiveness of extracellular glutamate to a cocaine injection. 3) Susceptibility of the cocaine induced motor responses to AMPA/kainate receptor blockade is present only in the cocaine-paired animals indicating that the cocaine-induced rise in extracellular glutamate may be functionally significant.

\section{Summary}

This study reveals that extracellular glutamate is elevated by a cocaine injection only in the environment where rats were pretreated with daily cocaine. Furthermore, only in the paired environment was the cocaine motor response inhibited by blocking AMPA/kainate receptors in the nucleus accumbens. The occurrence of these cocaine-induced effects only in the presence of environmental stimuli previously paired with repeated cocaine administration indicates a role for glutamate transmission in the nucleus accumbens in the environmental regulation of cocaine-induced behavior. In support of this notion, the elicitation of locomotor activity in experimental animals and of craving in cocaine addicts by cocaine-conditioned cues is associated with increased metabolism in cortical nuclei having glutamatergic projections to the nucleus accumbens (Brown et al. 1992; Grant et al. 1996; Childress et al. 1999). Taken together these data are consistent with a role for corticofugal glutamatergic afferents to the nucleus accumbens in modulating cocaine-induced motor activity by environmental stimuli.

\section{ACKNOWLEDGMENTS}

We wish to thank Carol Heissenbuttle for assisting in the preparation of this manuscript. This research was supported in part by USPHS grants MH-40817 and DA-03906, as well as a predoctoral NRSA DA-05642 (KB).

\section{REFERENCES}

Badiani A, Camp DM, Robinson TE (1997): Enduring enhancement of amphetamine sensitization by drugassociated environmental stimuli. J Pharmacol Exp Ther 282:787-794

Bardo MT (1998): Neuropharmacological mechanisms of drug reward: beyond dopamine in the nucleus accumbens. Critical Rev Neurobiol 12:37-67

Bell K, Kalivas PW (1996): Context-specific cross sensitization between systemic cocaine and intra-accumbens AMPA infusion in rats. Psychopharmacol 127:377-383

Browman KE, Badiani A, Robinson TE (1996): Fimbriafornix lesions do not block the development and the expression of amphetamine sensitization. Pharmacol Biochem Behav 53:899-902

Brown EE, Robertson GS, Fibiger HC (1992): Evidence for conditional neuronal activation following exposure to a cocaine-paired environment: role of forebrain limbic structures. J Neuroscience 12:4112-4121

Childress AR, Mozley PD, McElgin W, Fitzgerald J, Reivich M, O'Brien CP (1999): Limbic activation during cueinduced cocaine craving. Am J Psychiatry 156:11-18

Churchill L, Swanson CJ, Urbina M, Kalivas PW (1999): Repeated cocaine alters glutamate receptor subunits levels in the nucleus accumbens and ventral tegmental area of rats that develop behavioral sensitization. J Neurochem 72:2397-2403

Deutch AY, Bourdelais AJ, Zahm DS (1993): The nucleus 
accumbens core and shell: accumbal compartments and their functional attributes. In Kalivas PW, Barnes CD (eds), Limbic Motor Circuits and Neuropsychiatry. Boca Raton, FL, CRC Press, pp 45-88

Dietze S, Kuschinsky K (1994): Effect of conditioning with $\mathrm{d}$-amphetamine on the extracellular concentration of dopamine and its metabolites in the striatum of behaving rats. Naunyn-Schmiedeberg's Arch Pharmacol 350:22-27

Donzanti BA, Yamamoto BK (1988): An improved and rapid HPLC-EC method for the isocratic separation of amino acid neurotransmitters from brain tissue and microdialysis perfusates. Life Sci 43:913-914

Fitzgerald LW, Ortiz J, Hamedani AG, Nestler EJ (1996): Drugs of abuse and stress increase the expression of GluR1 and NMDAR1 glutamate receptor subunits in the rat ventral tegmental area: common adaptions among cross-sensitizing agents. JNeurosci 16:274-282

Ghasemzadeh MB, Nelson LC, Lu X-Y, Kalivas PW (1999): Neuroadaptations in ionotropic and metabotropic glutamate receptors by chronic cocaine. J Neurochem 72:157-165

Grant S, London ED, Newlin DB, Villemagne VL, Liu X, Contoreggi C, Phillips RL, Kimes AS, Margolin A (1996): Activation of memory circuits during cue-elicited cocaine craving. Proc Natl Acad Sci(USA) 93:1204012045

Jabaudon D, Shimamoto K, Yasuda-Kamatinai Y, Scanziani M, Gahwiler BH, Gerber U (1999): Inhibition of uptake unmasks rapid extracellular turnover of glutamate of nonvesicular origin. Proc Natl Acad Sci(USA) 96:87338738

Kalivas PW, Alesdatter JE (1993): Involvement of NMDA receptor stimulation in the VTA and amygdala in behavioral sensitization to cocaine. J Pharmacol Exp Ther 267:486-495

Kokkinidis L, Anisman H (1980): Amphetamine models of paranoid schizophrenia: an overview and elaboration of animal experimentation. Psychol Bull 88:551-579

Koob GF, Robledo P, Markou A, Caine SB (1993): The mescorticolimbic circuit in drug dependence and reward - A role for the extended amygdala? In Kalivas PW, Barnes CD (eds), Limbic Motor Circuits and Neuropsychiatry. Boca Raton, FL, CRC Press, pp 289-310

Li Y, Wolf ME, White FJ (1999): The expression of cocaine sensitization is not prevented by MK-801 or ibotenic acid lesions of the medial prefrontal cortex. Behav Brain Res 104:119-126

Milliken GA, Johnson DE (1984): Analysis of Messy Data. Volume I: Designed Experiments. New York, Lifetime Learning Publications

Nestler EJ, Hope BT, Widnell KL (1993): Drug addiction: a model for the molecular basis of neural plasticity. Neuron 11:995-1006

Paxinos G, Watson C (1986): The rat brain in stereotaxic coordinates, 2 edn. Academic Press, Academic Press

Pellegrino LK, Pellegrino AS, Cushman AJ (1979): A stereotaxic atlas of the rat brain. Plenum Press, Plenum Press

Pierce RC, Bell K, Duffy P, Kalivas PW (1996): Repeated cocaine augments excitatory amino acid transmission in the nucleus accumbens only in rats having developed behavioral sensitization. J Neurosci 16:1550-1560

Pierce RC, Kalivas PW (1997): A circuitry model of the expression of behavioral sensitization to amphetaminelike psychostimulants. Brain Res Rev 25:192-216

Pierce RC, Reeder DC, Hicks J, Morgan ZR, Kalivas PW (1998): Ibotenic acid lesions of the dorsal prefrontal cortex disrupt the expression of behavioral sensitization to cocaine. Neuroscience 82:1103-1114

Pulvirenti L, Swerdlow NR, Koob GF (1991): Nucleus accumbens NMDA antagonist decreases locomotor activity produced by cocaine, heroin or accumbens dopamine, but not caffeine. Pharmacol Biochem Behav 40:841-845

Reid MS, Berger SP (1996): Evidence for sensitization of cocaine-induced nucleus accumbens glutamate release. Neuroreport 7:1325-1329

Reid MS, Hsu KJ, Berger SP (1997): Cocaine and amphetamine preferentially stimulate glutamate release in the limbic system: Studies on the involvement of dopamine. Synapse 27:95-105

Reith MEA, Meisler BE, Sershen H, Lajtha A (1986): Structural requirements for cocaine congeners to interact with dopamine and serotonin uptake sites in mouse brain and to induce stereotyped behavior. Biochem Pharmacol 35:1123-1129

Ritz MC, Cone EJ, Kuhar MJ (1990): Cocaine inhibition of ligand binding at dopamine, norepinephrine and serotonin transporters: A structure-activity study. Life Sci 46:635-645

Robinson TE, Becker JB (1986): Enduring changes in brain and behavior produced by chronic amphetamine administration: A review and evaluation of animal models of amphetamine psychosis. Brain Res Rev 11:157-198

Robinson TE, Browman KE, Crombag HS, Badiani A (1998): Modulation of the induction or expression of psychostimulant sensitization by the circumstances surrounding drug administration. Neurosci Biobehav Rev 22:347-354

Robinson TE, Wishaw IQ (1988): Normalization of extracellular dopamine in the striatum following recovery from a partial unilateral 6-OHDA lesion of the substantia nigra: a microdialysis study in freely moving rats. Brain Research 450:209-224

Rocha BA, Fumagalli F, Gainetdinov RR, Jones SR, Ator R, Giros B, Miller GW, Caron MG (1998): Cocaine selfadministration in dopamine-transporter knockout mice. Nature Neuroscience 1:132-137

Rothstein J, Dykes-Hoberg M, Pardo CA, Brostol LA, Jin L, Kuncl RW, Hediger M, Kanai Y, Wang Y, Schielke JP, Welty DF (1996): Knockout of glutamate transporters reveals a major role for astroglial transport in excitotoxicity and clearance of glutamate. Neuron 16:675-686

Schenk S, Snow S (1994): Sensitization to cocaine's motor activating properties produced by electrical kindling of the medial prefrontal cortex but not of the hippocampus. Brain Res 659:17-22

Segal DS, Schuckit MA (1983): Animal models of stimulantinduced psychosis. In Creese I (ed), Stimulants: Neuro- 
chemical, Behavioral, and Clinical Perspectives. New York, Raven Press, pp 131-167

Smith JA, Mo Q, Guo H, Kunko PM, Robinson SE (1995): Cocaine increases extraneuronal levels of aspartate and glutamate in the nucleus accumbens. Brain Res 683:264269

Stewart J (1991): Conditioned stimulus control of the expression of sensitization of the behavioral activating effects of opiate and stimulant drugs. In Gormezano I, Wasserman EA (eds), Learning and memory: Behavioral and Biological Substrates. Hillside, NJ, Erlbaum,

Stewart J, Vezina P (1988): Conditioning and behavioral sensitization. In Kalivas PW, Barnes CD (eds), Sensitization in the Nervous System. Caldwell, NJ, Telford Press, pp 207-224

Timmerman W, Westerink BH (1997): Brain microdialysis of GABA and glutamate: what does it signify? Synapse 27:242-261

Warr O, Takahashi M, Attwell D (1999): Modulation of extracellular glutamate concentration in rat brain slices by cystine-glutamate exchange. J Physiol 514.3:783-793

Weiss SRB, Post RM, Pert A, Woodward R, Murman D (1989): Context-dependent cocaine sensitization: differential effect of haloperidol on development versus expression. Pharmacol Biochem Behav 34:655-661
White FJ, Hu X-T, Zhang X-F, Wolf ME (1995): Repeated administration of cocaine or amphetamine alters neuronal responses to glutamate in the mesoaccumbens dopamine system. J Pharmacol Exp Ther 273:445-454

White FJ, Kalivas PW (1998): Neuroadaptations involved in amphetamine and cocaine addiction. Drug Alc Depend 51:141-154

Wolf ME (1998): The role of excitatory amino acids in behavioral sensitization to psychomotor stimulants. Progress in Neurobiology 54:679-720

Wolf ME, Dahlin SL, Hu X-T, Xue C-J, White K (1995): Effects of lesions of prefrontal cortex, amygdala, or fornix on behavioral sensitization to amphetamine; comparison with N-methyl-D-asparatate antagonists. Neuroscience 69:417-439

Xue C-J, Ng JP, Li Y, Wolf ME (1996): Acute and repeated systemic amphetamine administration: effects on extracellular glutamate aspartate and serine levels in rat ventral regimental area and nucleus accumbens. J Neurochem 67:352-363

Zhang X-F, Hu X-T, White FJ, Wolf ME (1997): Increased responsiveness of ventral tegmental area dopamine neurons to glutamate after repeated administration of cocaine or amphetamine is transient and selectively involves AMPA receptors. J Pharmacol Exp Ther 281:699-706 